\title{
PLC BASED CONTROL \\ FOR WIND-POWERED GENERATION
}

\author{
Azzam, Attia E1-Sbaie \\ Faculty Engineering, Menoufia Univ., Shibeen El-kom, Egypt
}

\section{Abstract:}

In spite of many advantages of an asynchronous generator, its use in isolated systems has been very limited due to the difficulties involving in controlling the variation of its generated voltage and frequency due to variation of load current.

This paper gives the possibility to minimize the variation of the output voltage and frequency. The technique utilize an algorithmis implemented using PLC devices.

PLC has the resposibility of the system sequence control for output voltage and frequency.

The system functions were analized and implemented in PLC based hardware and software. The control system was tested systematically in the laboratory and shows excellent performance.

\footnotetext{
Manuscript received from Dr AZZAM, ATTIA EL-SBAIE on : 11/4/2000 Accepted on : $5 / 6 / 2000$

Engineering Research Bulletin, Vol 23,No 3, 2000 Minufiya University, Faculty of Engineering, Shebien El-Kom, Egypt, ISSN 1110-1180
} 


\section{INTRODUCTION:}

When an asynchronous machine works as a motor connected to the power system, the frequency of output voltage doesn't affect the behavior of the machine because it can be considered constant. Even in the case of working as a generator connected to an infinate power network, output frequency is fixed, since it is determined by the power system[2].

However, when the machine operates isolated from the network, frequency plays a fundamental role in the overall system its value will fluctuate according to demanded load and wind turbine speed.

The variation of the load current will cause variation in output voltage for different capacitors Fig. (1) and in output frequency for different resistances. Fig. (2) [2].

This paper deals with the PLC based control of a windpowered generator based on a self excited asynchronous machine and designed to be operated in isolation from the power network.

To achieve the objective, a complete set of instruments has been designed; where the wind-turbine is simulated by a controlled induction motor, and the wind condition will be manually changed.

A set of capacitors controlled through a series of contactors triggered from the PLC is used for reactive energy generation.

Another set consists of stepped resistance is also used to absorb excess power supplied by the generator when the wind conditions are excessive or the load connected by the user is too low. The set will be controlled also through a series of contactors triggered from the PLC and will be used as an active energy generation.

The generator is a conventional induction motor operates as a self-excited asynchronous generator; its load consists of series of resistive load. The control PLC is connected to a PC where the control algorithm is inplemented. 


\section{MODELLING SYSTEM \& ANALYSIS:}

The design of the system modelling gives us the possibility to observe the behaviors of different parts of the generating system such as turbine, generator, reactive energy sources and control system. That means, the different elements of the system are separately modelled by using standard technique that could be easily emulate the behaviors of real the devices in a plant that is shown in Fig.(3) .

\subsection{WIND DRIVEN-TURBINE:}

The wind-driven turbine is emulated by means of a commercial induction motor that is fed by a controlled converter. Using this way, the change the converter speed reference is possible to simulate different load states, which are corresponding to different levels of wind that is applied on the turbine.

\subsection{ASYNCHRONOUS GENERATOR:}

An induction motor is used as generator. The advantage of the asynchronous generator over the synchronous machine in isolated installation are major; lower cost, very high robustness, low maintenance and a good power-weight ratio which allows easy transportation to remote places[1].

The main disadvantages of this type of machines are directly related to the need to use capacitors for the production of reactive energy, to voltage and frequency control and to starting up of the self-excited machine.

Generated voltage depends on generator speed, connected capacity, load current and power factor. Moreover, generated frequency is not simply a function of generator speed but also depends on load[3]. 


\subsection{STEPPED BANK OF CAPACITOR:}

Since the total capacity applied to the generator must be modified in relation to its speed and load conditions, a stepped capacitor bank has been designed. This bank is operated by means of switches, controlled by the PLC. It has been designed in such a way that over voltages higher than $\pm 2.5 \%$ of rated voltage are never permitted.

In order to eliminate peak currents produced during the connection of the bank of capacitors a set of protection reactances are series connected to the bank. This type of coil exhibits the property of not influencing on the system when it works at the normal rated frequency at this frequency the coils present a very low impedance.

However, on the connection of the capacitors, the limit of maximum current, protecting both, the bank of capacitors and the rest of the installation.

Likewise, the capacitor steps are provided with discharge resistances in order to avoid personal risks, once the capacitor bank has been disconnected. Moreover, these discharge resistnces are useful for the system operation, since they prevent the appearance of over currents during the connection of the capacitor steps.

\subsection{SET OF LOADS:}

In order to operate the generator under load conditions two sets of loads have been designed; the first one is the user load, which consists of a group of resistive loads. The second one consists of a set of stepped resistances and is used to absorb excess power supplied by the generator when the wind conditions are excessive or the load connected by the user is too low. It must be remembered that the generated frequency is function of the load, 
therefore depending on the power demanded by the user and the wind level, it can be necessary to apply additional energy consumption to keep the frequency at its maximum limits.

\section{CONTROL SYSTEM:}

The control system brain is based on low cost PLC in addition to some circuits (transformer, rectifier, frequency to voltage converter and analog to digital converter) to be compatible with the whole plant that is shown in Fig.(3). The main function of PLC is to control both, generated voltage and frequency keeping both variables around $220 \mathrm{v}$. and $50 \mathrm{HZ}$ respectively[5].

\subsection{VOLTAGE CONTROL:}

In order to allow a good system behavior even under unbalanced load conditions, the three-phase voltage of the generator must be converted into a continuous voltage between 0 and $10 \mathrm{v}$. to be compatible with $\mathrm{A} / \mathrm{D}$ conversion and PLC. To achieve this, the generator output voltage reduced by means of a transformer, then the obtained signals are rectified and filtered in order to eliminate the $\mathrm{AC}$ component.

In general terms generator output voltage depend on the capacity connected at its output. Thus, when capacity increases the reactive energy supplied to generator increases too, therefore, output voltage is higher. The PLC will act on the capacity banks, connecting or disconnecting the different steps of capacitors, and thereby regulating the level of output voltage. Fig.(4).

When designing the bank of capacitors that will be used as a reactive energy source, it must be taken into account that a minimum capacity exist, which allows the machine to operate as a generator. The minimum capacity must be calculated with the purpose of designing the set of capacitors that will be permanently connected to the generator. The effective capacity will be the capacity needed to produce the output rated voltage, even in the most adverse conditions of generating. 
Eq.(1), (2) have been suggested and driven to show the effective capacitance. From capacity bank that to be connected by PLC for suitable step to get minimum variation, and to get regulated level output voltage at different load current.

$$
\mathrm{C}_{\text {eff }}=\mathrm{C}_{\min }+\mathrm{C}_{\mathrm{st}} \quad \underline{(1)} \quad, \mathrm{C}_{\mathrm{st}}=\mathrm{C}_{\mathbf{0}} * \sum_{i=0}^{i=N-1} 2^{i} * \mathrm{~K}_{\mathrm{i}}
$$

\section{Where}

$\mathrm{C}_{\mathrm{eff}}$ : Will be needed to produce the output rated voltage even in the most adverse Conditions of generating.

$\mathrm{C}_{\min } \quad$ A minimum capacitance exists that will be permanently connected to the generator.

$C_{0} \quad$ Is the minimum capacitance's set.

$\mathrm{C}_{\text {st. }}$. The sum of the involved capacitance for that step.

$\mathrm{N} \quad$ The maximum number of sets.

$\mathrm{K}_{\mathrm{i}} \quad$ Is a digital factor, equal ( 0 ) for the disconnected capacitors branch , and equal (1), for connected capacitors.

Where $i$ is the number of branch which be connected or disconnected.

\subsection{FREOUENCY CONTROL:}

The frequency of the output voltage essentially depends on the generator speed, which is proportional to the rotating speed of the turbine. When the load in the terminals of the generator increases the active power absorbed by this increase and therefore, the resistant torque of the generator increases too. This increment of 
the torque of the generator produces the braking of the turbine and, consequently the frequency decreases. For the above reasons, to control generator frequency the PLC acts on the resistance bank, changing active power supplied by the generator. Fig.(5).

If we accept the possibility of a total absence of user load during the operation of the generator, the set of stepped resistances must be capable of dissipating all excess energy generated and not consumed by the user load.

Eq.(3) has been suggested and driven to show the effective resistance from the resistor bank that to be connected by PLC for suitable step to get minimum variation of the output frequency at different load current.

$$
\mathbf{R}_{\text {eff }}=\mathbf{R}_{\mathbf{0}} / \sum_{i=0}^{i=N-1} 2^{i} * K_{i}
$$

\section{Where:}

$\mathrm{R}_{\text {eff }} \quad$ Will be needed to produce the output rated frequency.

$\mathrm{R}_{0} \quad$ Is the maximum resistance set.

$\mathrm{N} \quad$ The maximum number of sets.

$\mathrm{K}_{\mathrm{i}} \quad$ (As defined in previous Equation (2).) 


\section{CONCLUSIONS:}

ㅁ The output voltage variation of the simulated wind-turbine is controlled to be in te range of $\pm 2.5 \%$ for different load current. In the other hand the output frequency variation is controlloed to be $\pm 0.2 \%$ for different load current also.

a Control of the system is performed by a PLC that executes the control algorithms.

- The control parameters can be altered, so the behavior of the system under different types of the controller can be investigated.

\section{REFERENCES:}

[1] D.W. Novotny, D.J. Gritter, G.H. studtman; Self-exitation in inverter driven induction machines, IEEE Trans. on power App. and System Vol.PAS-96, no.4,pp.1117-1125,1977.

[2] F.E. Abdel-kader; The reluctance machine as a self-excited reluctance geneerator, Electric machines and power systems, Vol.10, No.2, pp.141 $-148,1985$.

[3] M.G. simoes , B.K.Bose, RJ.spiegel; Design and performance evaluation of a fuzzy-logic-based variable-speed wind generation system, IEEE Trans. on Ind.Appl., vol.33, no.4,PP.956,965,1997.

[4] M.S. Miranda et al ., wind powered pumping system using induction machines with pulse width modulation (PWM) excitation, Proc. $7^{\mathrm{TH}}$ EPE. Trondheim, norway, pp. 2.637-2.641, 1997.

[5] Melero.M.G.et al.: A protection and control system for. asynchronous motor based on PLC, SD EMPED 97, The IEEE 1997 international simposium on diagnostics for electrical machines, power electronics and drives. sep. 1997 carry Le Rouet France. 


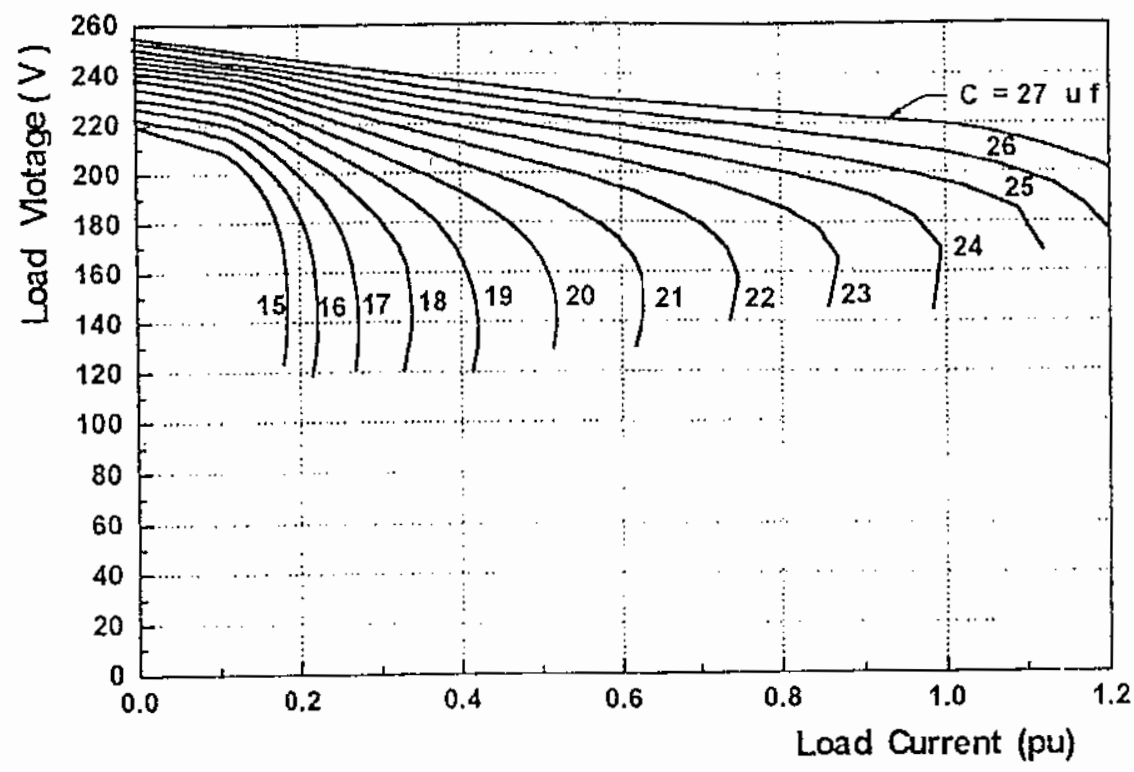

Fig. (1) The output voltage for different capacitors with the variation of the load current (PU)

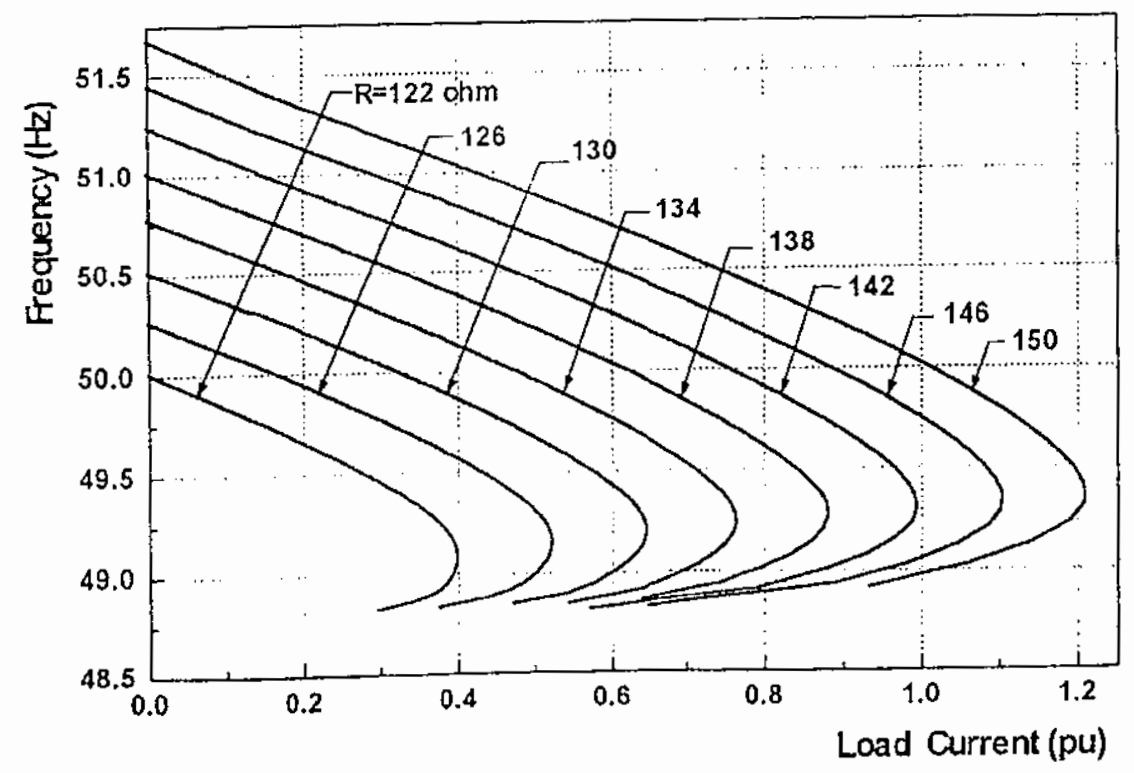

Fig. (2) The output frequency for different resistance with the variation of the load current $(\mathrm{PU})$ 


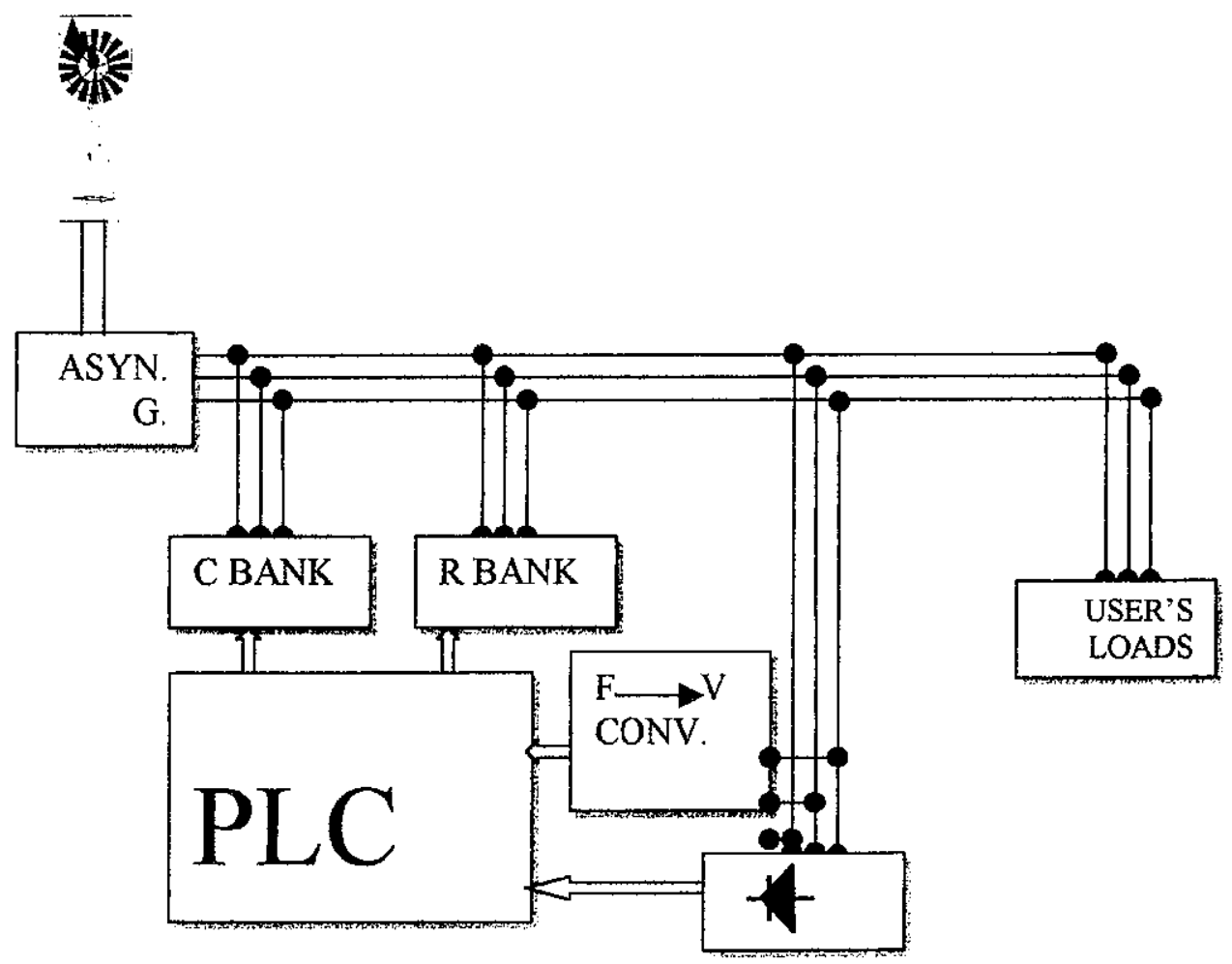

Fig.(3) System architecture 


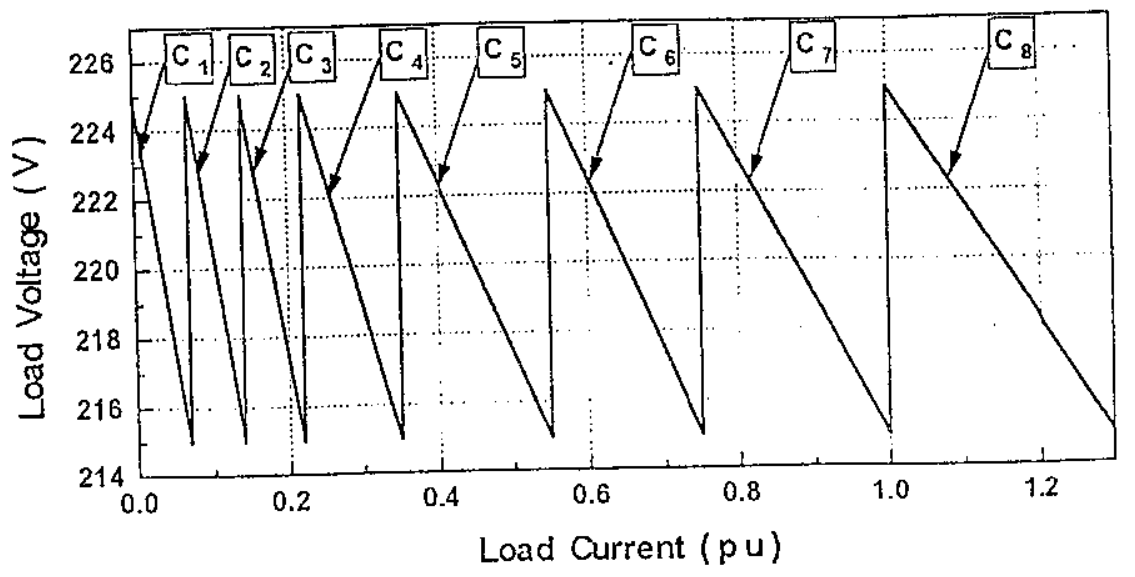

Fig.(4) Regulating the level of the output voltage

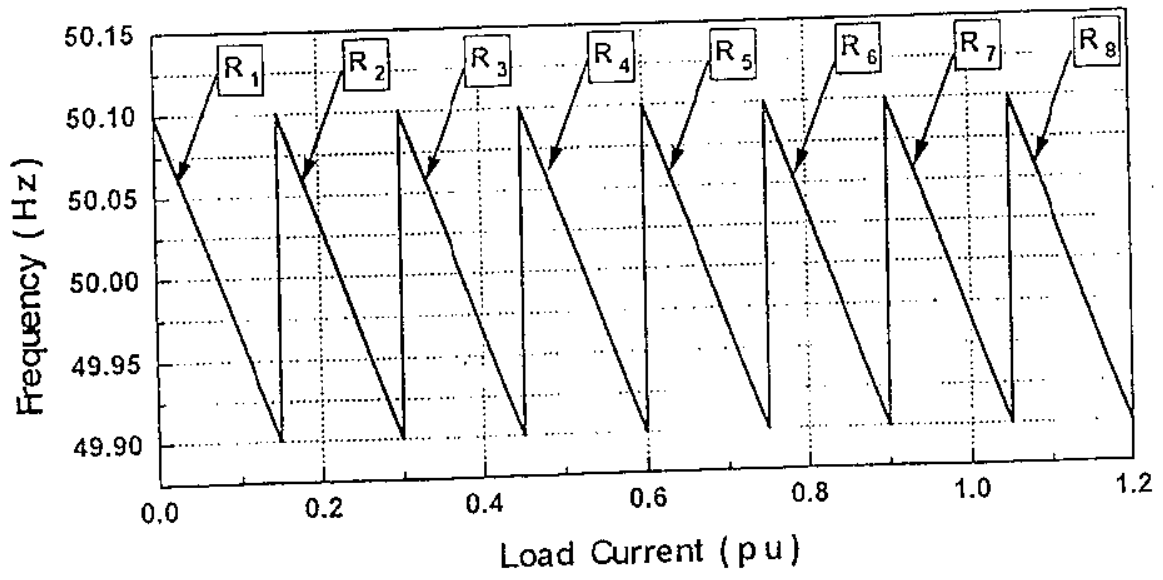

fig. (5) Controlling of the generator frequency. 


\title{
بسم الله الرممل الروييم
}

\section{التجكم في مولداتث القدرة بطاقة الرياح}

باستخدام الحاكمات المنطقية المبريجة

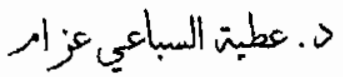 \\ قسم الهندسة الكهربية - كلة المندسة بشبين الكوم - جادعة المنوفية - مصر
}

\section{كنكرة البهث:}

طاقة الرياح هي إحدى مصادر الطاقة الجديدة و المتجددة و التي يبحث عنها

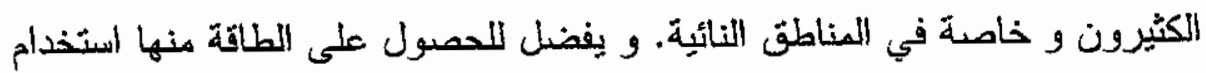

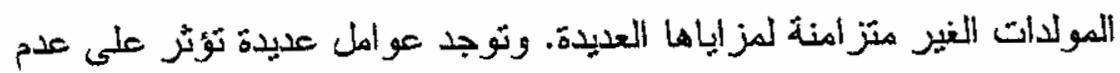

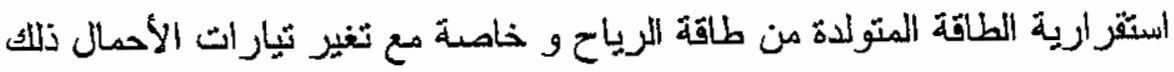
بسبب تغير التردد ، و تغير الجهد الصنادر عن تلاك المولدات.

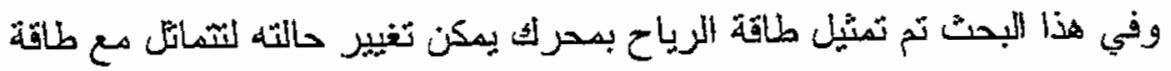

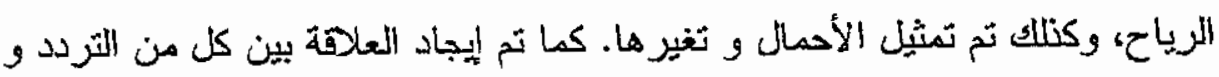
تيار الحمل ، وكذلك بين الجهاح و تئار الحمل.

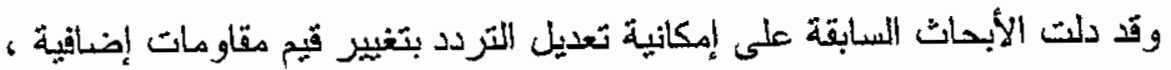

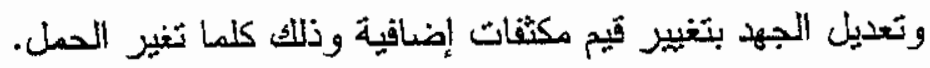

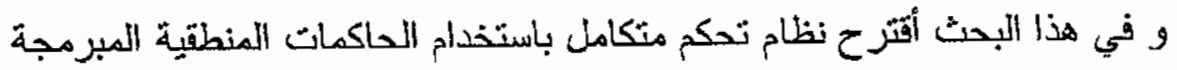
هارد وير (HW) و سوفت وير (SW) لضبط الجهد عند ، بr فولت ، وبأقصىى قيمة

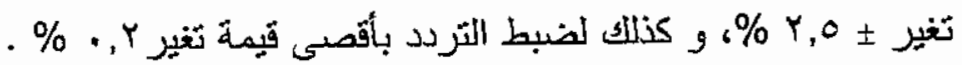

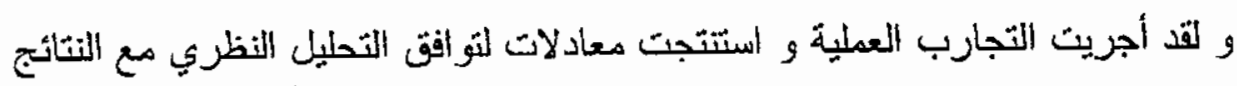

